\title{
ORIGINAL
}

\section{Clinical features of insulinoma in patients with multiple endocrine neoplasia type 1: analysis of the database of the MEN Consortium of Japan}

\author{
Akihiro Sakurai ${ }^{1), 2)}$, Masanori Yamazaki ${ }^{2)}$, Shinichi Suzuki ${ }^{3)}$, Toshihiko Fukushima ${ }^{3)}$, Tsuneo Imai ${ }^{4)}$, \\ Toyone Kikumori ${ }^{4)}$, Takahiro Okamoto ${ }^{5)}$, Kiyomi Horiuchi ${ }^{5)}$, Shinya Uchino ${ }^{6}$, Shinji Kosugi ${ }^{7)}$, \\ Masanobu Yamada ${ }^{8)}$, Izumi Komoto ${ }^{9)}$, Kazuhiro Hanazaki ${ }^{10)}$, Masatsune Itoh ${ }^{11)}$, Tatsuya Kondo ${ }^{12)}$, \\ Masatomo Mihara $^{13)}$ and Masayuki Imamura ${ }^{9)}$ \\ ${ }^{1)}$ Department of Medical Genetics, Shinshu University School of Medicine, Matsumoto 390-8621, Japan \\ ${ }^{2)}$ Division of Diabetes, Endocrinology and Metabolism, Department of Internal Medicine, Shinshu University School of Medicine, \\ Matsumoto 390-8621, Japan \\ 3) Department of Breast, Endocrine and Thyroid Surgery, Fukushima Medical University, Fukushima 960-1295, Japan \\ 4) Department of Breast and Endocrine Surgery, Nagoya University Hospital, Nagoya 466-8550, Japan \\ 5) Department of Endocrine Surgery, Tokyo Women's Medical University, Tokyo 162-8666, Japan \\ 6) Noguchi Thyroid Clinic and Hospital Foundation, Beppu 874-0932, Japan \\ 7) Department of Medical Ethics/Medical Genetics, Kyoto University School of Public Health, Kyoto 606-8501, Japan \\ 8) Department of Medicine and Molecular Science, Gunma University Graduate School of Medicine, Maebashi 371-8511, Japan \\ ${ }^{9)}$ Department of Surgery, Kansai Electric Power Company Hospital, Osaka 553-0003, Japan \\ ${ }^{10)}$ Department of Surgery, Kochi Medical School, Kochi University, Nankoku 783-8505, Japan \\ 11) Department of Pediatrics, Kanazawa Medical University, Uchinada 920-0293, Japan \\ ${ }^{12)}$ Department of Metabolic Medicine, Kumamoto University Faculty of Life Sciences, Kumamoto 860-8556, Japan \\ 13) Department of Molecular Endocrinology and Metabolism, Tokyo Medical and Dental University, Tokyo 113-8519, Japan
}

\begin{abstract}
More than 50\% of patients with multiple endocrine neoplasia type 1 (MEN1) develop gastroenteropancreatic neuroendocrine tumors (GEPNETs), and insulinoma is the second most common functioning GEPNET. Compared to other functioning and nonfunctioning GEPNETs in MEN1, insulinoma is considered to develop at a younger age. To clarify the clinical features of insulinoma developed in Japanese patients with MEN1, a recently constructed database of Japanese MEN1 patients was analyzed. Among 560 registered cases, insulinoma was seen in 69 patients and information on age at diagnosis was available for 54 patients. Tumors predominantly occurred in the body and tail of the pancreas. The mean age at diagnosis of insulinoma $(34.8 \pm 16.7 \mathrm{yrs})$ was significantly younger than that of gastrinoma $(50.6 \pm 14.3 \mathrm{yrs})$ and nonfunctioning tumor $(44.7 \pm 13.3 \mathrm{yrs})$ in patients with MEN1. Patients diagnosed as having insulinoma during middleage (30 - $49 \mathrm{yrs}$ ) tended to have a long period from appearance of hypoglycemic symptoms to diagnosis of the tumor. Of note, 13 patients $(24 \%)$ were diagnosed as having insulinoma before $20 \mathrm{yrs}$ of age. Such young onset was not seen in other GEPNETs. Since the development of GEPNETs during adolescence is quite rare, insulinoma diagnosed before 20 yrs strongly suggests the presence of MEN1 and warrants further investigation, including MEN1 genetic testing. Also, clinicians should be aware that insulinoma can often be missed in middle-aged patients.
\end{abstract}

Key words: Multiple endocrine neoplasia type 1 (MEN1), Database, Adolescence, Hypoglycemia

MULTIPLE ENDOCRINE NEOPLASIA TYPE 1 (MEN1) is an autosomal dominantly inherited endocrine tumor syndrome characterized by tumor development in various endocrine- and non-endocrine organs

Submitted May 2, 2012; Accepted May 30, 2012 as EJ12-0173 Released online in J-STAGE as advance publication Jun. 16, 2012 Correspondence to: Akihiro Sakurai, M.D., Ph.D., Shinshu University School of Medicine, 3-1-1 Asahi, Matsumoto 390-8621, Japan. E-mail: aksakura@shinshu-u.ac.jp such as parathyroid hyperplasia, gastroenteropancreatic neuroendocrine tumor (GEPNET), anterior pituitary adenoma and adrenal cortex adenoma $[1,2]$. Less frequent tumors include cutaneous tumor, lipoma, and thymic- and bronchial neuroendocrine tumors. MEN1 is clinically diagnosed by confirming neoplastic diseases in at least two of the commonly affected organs, namely, parathyroid, endocrine pancreas and anterior pituitary [3]. For family members of the patient, the 
presence of one lesion is sufficient to establish a diagnosis. Most subjects with MEN1 carry a heterozygous germline mutation in the MEN1 gene, which localizes to chromosome 11q13 [4]. The MEN1 gene consists of 10 exons and encodes the 610 amino-acid nuclear protein menin [5]. Based on data on the incidence of primary hyperparathyroidism (PHPT) and other epidemiological studies, the prevalence of MEN1 in western countries has been estimated to be about 2-3 cases/100,000 individuals [6].

PHPT is the most common, and usually the initial manifestation of MEN1 [7]. Its prevalence during lifetime for gene carriers is nearly $100 \%$ and the average age of onset is during the third decade of life, about 30 years earlier than sporadic primary hyperparathyroidism [8].

GEPNET is the second most common endocrine manifestation in MEN1 after PHPT, and its prevalence is about $50-60 \%[3,9,10]$. Since many patients with PHPT remain asymptomatic, GEPNET can be the initial manifestation that leads to the diagnosis of MEN1 in up to $50 \%$ of patients $[11,12]$. The most common form of functioning GEPNET in MEN1 is gastrinoma, which exists predominantly in the duodenal mucosa. Other forms of functioning tumors seen in MEN1 include insulinoma, glucagonoma, somatostatinoma and VIPoma. Nonfunctioning tumors are also common and usually multiple in MEN1.

Among GEPNETs in MEN1, insulinoma is considered to develop during early age $[1,9]$. Compared to other MEN1-related GEPNETs, insulinoma occurs more often in patients younger than 40 years old, and therefore could be the initial manifestation. Accordingly, early recognition of insulinoma could lead to early diagnosis of MEN1 in patients.

To ascertain the clinical features and current management of MEN1, and to provide information useful to clinicians facing difficulties in managing MEN1 patients, we established a MEN study group in 2008 designated the "MEN Consortium of Japan", and constructed a database of Japanese patients with MEN [10]. Here we report clinical features of insulinoma in patients with MEN1 who were registered in the database of the MEN Consortium of Japan.

\section{Patients and Methods}

We analyzed the clinical data of patients with MEN1 collected by the MEN Consortium of Japan. Procedure of data collection and general characteris- tics of patients with MEN1 have been recently reported [10]. Physicians and surgeons in Japan reported clinical information of their MEN1 patients according to questionnaires provided by the MEN Consortium. The study was reviewed and approved by the Institutional Review Board of Shinshu University School of Medicine.

After verification of registered data, 560 cases were considered eligible for the analysis. Data on patients with GEPNETs were extracted from the database and the clinical features were analyzed. Because of the retrospective design, the diagnostic criteria of MEN1related tumors could have varied between hospitals. Thus we judged appropriateness of diagnosis of insulinoma by confirmation of inappropriate hypersecretion of insulin, amelioration of clinical symptoms after surgery, and results of immunostaining of the resected tumor. When diagnosis of insulinoma was uncertain or registered information was insufficient, data was verified by directly communicating with attending physician of each patient. Results are expressed as mean \pm SD. Since most of our data was not normally distributed, significance of differences was determined by MannWhitney-Wilcoxon test or Fisher's exact test wherever appropriate. $p<0.05$ was considered significant.

\section{Results}

\section{General features of insulinoma in MEN1}

As previously reported [10], GEPNETs were diagnosed in 314/536 patients (58.6\%), excluding 24 patients diagnosed by presymptomatic genetic testing. Insulinoma was diagnosed in 69 patients, among whom 41 patients had clinically proven hypoglycemia or clinical histories symptomatic of hypoglycemia prior to diagnosis. Asymptomatic hypoglycemia was identified during initial work-up for MEN1 or during surveillance in majority of other patients.

Information on localization of the tumor was available for 41 patients. Only three (7\%) patients had insulinoma in the pancreas head and $30(73 \%)$ patients developed insulinoma in the distal portion of pancreas. Eight (20\%) patients had multiple insulinomas existing in both the head and body-tail region of the pancreas. Information on the tumor size was obtained from 29 patients and ranged from $1.5 \mathrm{~mm}$ to $94 \mathrm{~mm}(25.4 \pm 19.5 \mathrm{~mm})$.

Surgical resection of insulinoma was performed for $91 \%(63 / 69)$ of patients, a proportion significantly higher than that for gastrinoma $(52 \%)$ or for nonfunctioning tumor $(34 \%)$. Operative procedures are summarized in 
Table 1. Given that the majority of insulinoma occurred in the body or tail of the pancreas, distal pancreatectomy is the most commonly selected procedure, followed by enucleation of the tumor. Localization of the tumor was not provided for 28 patients, which probably reflects incomplete clinical record such as loss of old chart or change of hospital during clinical course. Indeed, 9 patients underwent distal pancreatectomy, indicating that they had insulinoma in the pancreas tail. It is possible that exact localization of the tumor was unable to determine in some patients because the tumor was too small to detect by imaging study. Reoperation was performed for 8 patients due to metachronous tumor development.

Information on pathological diagnosis was given for 38 patients. Diagnosis of well-differentiated endocrine tumor and well-differentiated endocrine carcinoma was made for 18 and 1 patients, respectively. In other 19 patients, tumor was pathologically diagnosed as adenoma. No tumors were pathologically diagnosed as either endocrine cancer or poorly differentiated endocrine carcinoma. One patient with "malignant insulinoma" was registered, but pathological information was not given.

\section{Age at diagnosis of insulinoma}

Ages at diagnosis of insulinoma, gastrinoma and nonfunctioning tumor are summarized in Table 2 and Fig. 1. Since nonfunctioning tumors frequently accompany other functioning tumors, patients with nonfunctioning tumors only are included in the "nonfunctioning tumor" group. Patients included in the "insulinoma" and "gastrinoma" groups may have other functioning- or nonfunctioning tumors. For example, patients having both insulinoma and gastrinoma are included in both groups.

The average age at diagnosis of GEPNETs in Japanese patients with MEN1 was $44.7 \pm 15.6$ years, about 10 years younger than sporadic patients $[13,14]$. When compared based on function of the tumor, insulinoma in MEN1 was diagnosed significantly earlier than gastrinoma and nonfunctioning tumor in MEN1 (Table 2). In insulinoma, there was no discernible peak age of diagnosis and it varied widely from the second to sixth decade of life. 33/54 (61\%) patients were diagnosed before age of 40 (Fig. 1), consistent with a previous report [9]. In the database of MEN Consortium of Japan, 16 patients developed GEPNETs before age 20 yrs, 13 of which had insulinoma. The other two patients had nonfunctioning tumors, and information on the function of the tumor was not available in one patient.

Mean ages at first appearance of hypoglycemic symptoms and at diagnosis of insulinoma are shown in Fig. 2. Insulinoma was diagnosed within 1 year from the onset of hypoglycemic symptoms in about $50 \%$ of patients. In a significant number of patients however, a long period - up to 30 years in one case - elapsed between the appearance of symptoms and the diagnosis of insulinoma. The delay in diagnosis was particularly evident in patients diagnosed with insulinoma between age 30 and early 50 s and was observed in both probands and family members. The delay in diagnosis of insulinoma is well known and the mean duration of symptoms at diagnosis has been reported as 3 - 4 years $[15,16]$, while the age dependence of the delay in diagnosis has not previously been demonstrated.

Table 1 Surgical procedure undertaken for insulinoma in patients with MEN1

\begin{tabular}{lcc}
\hline procedure & $\begin{array}{c}\text { number of } \\
\text { patients }\end{array}$ & $(\%)$ \\
\hline distal pancreatectomy & 20 & 32 \\
tumor enucleation & 14 & 22 \\
distal pancreatectomy plus tumor enucleation & 5 & 8 \\
total pancreatectomy & 2 & 3 \\
others & 2 & 3 \\
unknown & 20 & 32 \\
\hline
\end{tabular}

Table 2 Age at diagnosis of GEPNETs registered with the MEN Consortium of Japan database

\begin{tabular}{|c|c|c|c|c|c|}
\hline & \multirow{2}{*}{ insulinoma } & \multirow{2}{*}{ gastrinoma } & \multirow{2}{*}{ NF tumor } & \multicolumn{2}{|c|}{ insulinoma $v s$. others } \\
\hline & & & & vs. gastrinoma & $v s . \mathrm{NF}$ tumor \\
\hline all $\left(\mathrm{yr}^{\mathrm{a}}\right)$ (range) & $34.8 \pm 16.7(8-68)$ & $50.6 \pm 14.3(20-78)$ & $44.7 \pm 13.3(19-74)$ & $p<0.001$ & $p=0.001$ \\
\hline proband $\left(\mathrm{yr}^{\mathrm{a}}\right)$ (range) & $37.6 \pm 19.0(9-68)$ & $47.9 \pm 13.4(20-74)$ & $47.9 \pm 12.0(19-74)$ & $p=0.017$ & $p=0.068$ \\
\hline family member $\left(\mathrm{yr}^{\mathrm{a}}\right)$ (range) & $29.3 \pm 13.0(8-47)$ & $56.2 \pm 14.4(33-78)$ & $40.8 \pm 14.1(22-71)$ & $p<0.001$ & $p=0.022$ \\
\hline proband $v s$. family member & $p=0.136$ & $p=0.030$ & $p=0.038$ & & \\
\hline
\end{tabular}




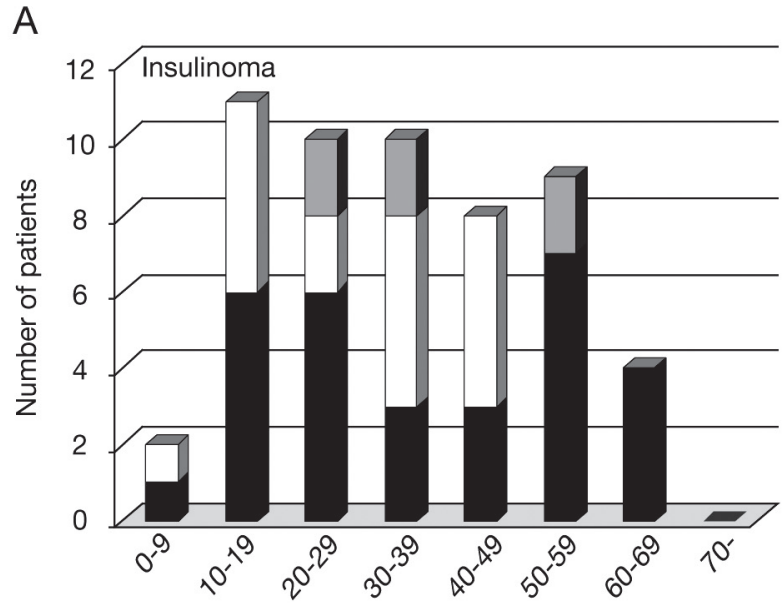

$\mathrm{B}$
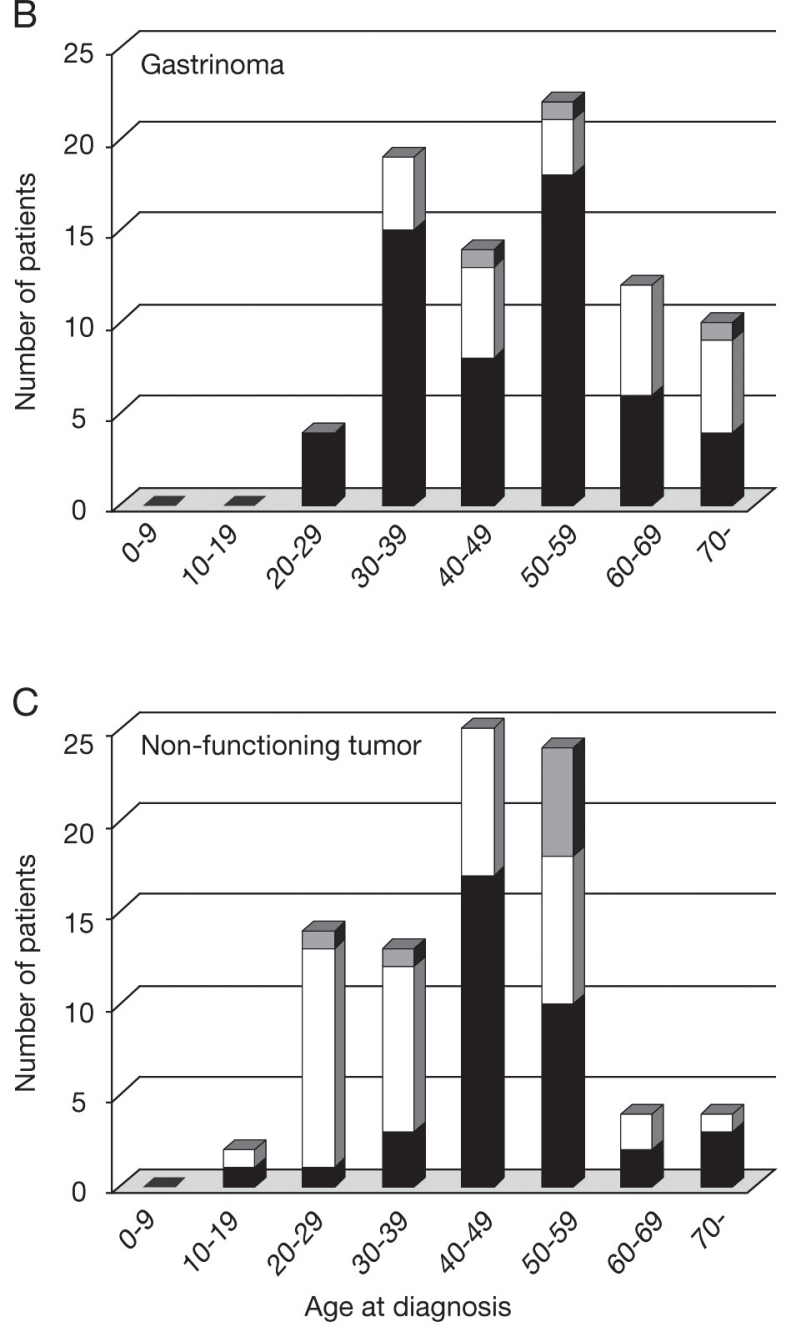

Fig. 1 Age at diagnosis of GEPNETs in patients with MEN1 Number of patients who developed insulinoma (A), gastrinoma (B) and non-functioning tumor (C) and their age at diagnosis is shown. Closed bar, open bar and gray bar represent proband, family member and patient without information of family history, respectively.

\section{Age dependence of clinical features}

Patients with insulinoma could be categorized into three groups according to their age at diagnosis of insulinoma: (1) a younger group diagnosed before age 30 with a short symptomatic period before diagnosis; (2) a middle-aged group with a lengthy symptomatic period before diagnosis, and (3) an aged group who had a brief or non-existent symptomatic period before diagnosis. A comparison of the three groups is summarized in Table 3. Only patients whose age at diagnosis of insulinoma was available are shown. In the younger group, 13 patients (57\%) were probands, that is, no family members had been previously diagnosed with MEN1 when insulinoma was detected in these individuals. In the middle-aged group, 6/18 (33\%, $p=$ $0.19 v s$. younger group) individuals were probands. In the aged group, 11 patients $(85 \%, p=0.03 v s$. younger group) were probands. Information on family history was not available for the other two patients. 51 patients (94\%) had undergone surgery followed by pathological confirmation of insulinoma. Due to the development of multiple tumors, the majority of patients in the middle-aged- and aged groups had undergone partial pancreatectomy, while enucleation of the tumor was performed in 13 of 23 patients $(57 \%)$ in the younger group. The proportion of patients who had undergone enucleation was significantly higher in the younger group compared to that of the middle-aged group (2/18, $11 \%, p<0.01 v s$. younger group) but was not statistically different from that in the aged group $(4 / 13,31 \%$, $p=0.18 v s$. younger group). The age at diagnosis of PHPT increased along with increasing age at diagnosis of insulinoma, reflecting the fact that PHPT and insulinoma were simultaneously identified in many of middle-aged- and aged group patients. The status of the MEN1 gene had been analyzed in most patients and pathologic germline mutations were identified in all but 3 patients (mutation positive rate $92.5 \%$ ).

\section{Discussion}

In the present study, we used a recently established database of Japanese MEN1 patients [10] to analyze the clinical features of insulinoma in these patients. After gastrinoma, insulinoma is the second most frequent functioning GEPNET in MEN1, and is often the first symptom which patients with MEN1 experience. The average age of onset of insulinoma is younger than other MEN1-related GEPNETs and it 


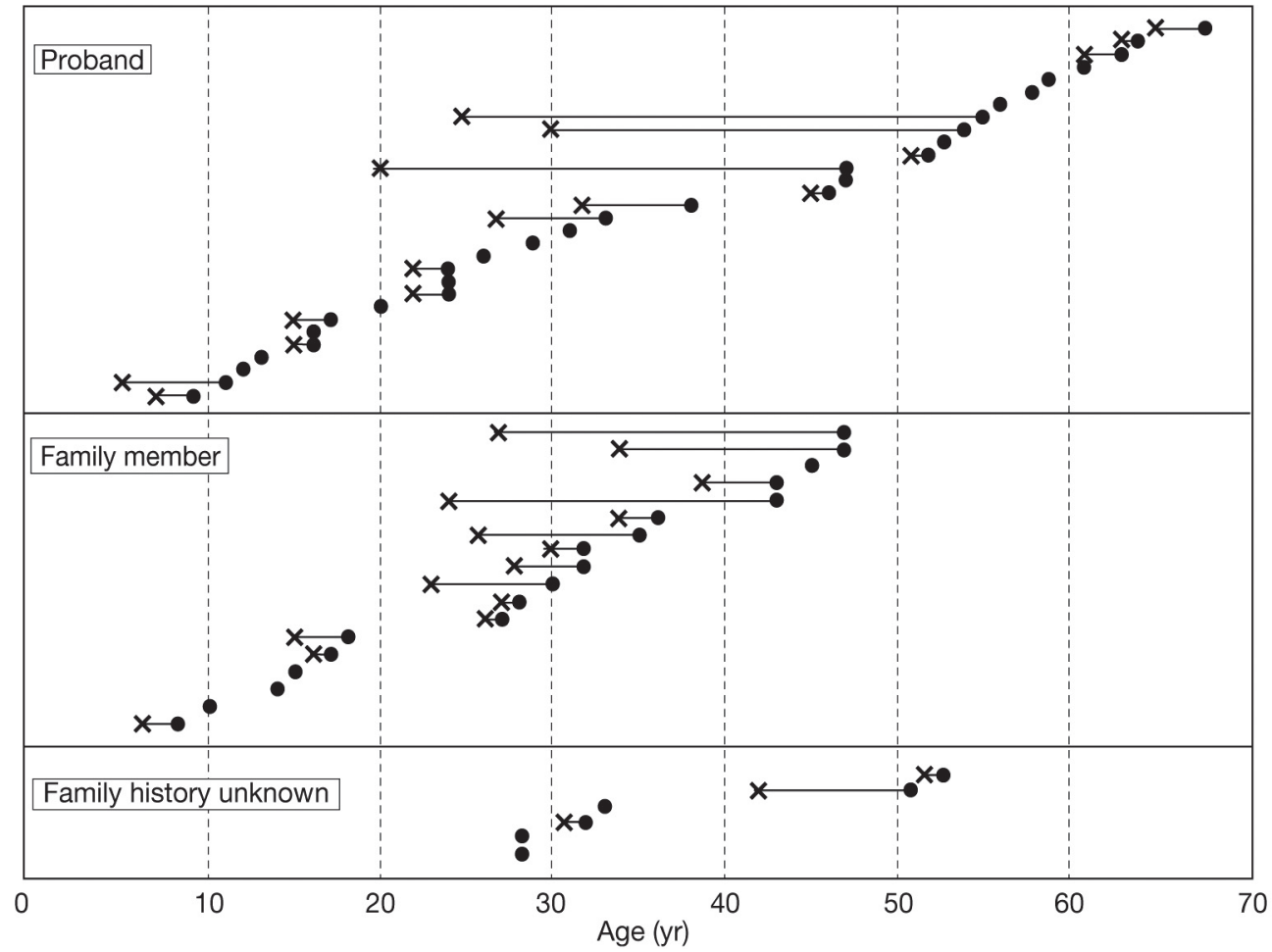

Fig. 2 Age at appearance of hypoglycemic symptom and diagnosis of insulinoma in patients with MEN1

Age at appearance of hypoglycemic symptoms and diagnosis of insulinoma in each patient was shown. Each closed circle represents a single patient and aligned according to the age at diagnosis of insulinoma. $\mathrm{X}$ represents age at appearance of hypoglycemic symptoms or confirmation of hypoglycemia, and is shown only if insulinoma was diagnosed more than one year after the appearance of hypoglycemic symptoms.

Table 3 Comparison of patients with insulinoma diagnosed at different age

\begin{tabular}{|c|c|c|c|}
\hline age at diagnosis of insulinoma & $\begin{array}{l}\text { before } 30 \text { yrs } \\
\text { (younger group) }\end{array}$ & $\begin{array}{c}30-49 \text { yrs } \\
\text { (middle-aged group) }\end{array}$ & $\begin{array}{l}50 \text { yrs or older } \\
\text { (aged group) }\end{array}$ \\
\hline number of patients & 23 & 18 & 13 \\
\hline${ }^{\text {sex }}$ male/female & $12 / 11$ & $4 / 14$ & $6 / 7$ \\
\hline $\begin{array}{l}\text { family history } \\
\text { proband/family member/unknown }\end{array}$ & $13 / 8 / 2$ & $6 / 10 / 2$ & $11 / 0 / 2$ \\
\hline age at diagnosis of insulinoma $\left(\mathrm{yr}^{\mathrm{a}}\right)$ (range) & $19.0 \pm 6.9(8-29)$ & $38.7 \pm 6.7(30-47)$ & $57.4 \pm 5.3(51-68)$ \\
\hline $\begin{array}{l}\text { duration between appearance of } \\
\text { symptom and diagnosis }\left(\mathrm{yr}^{\mathrm{a}}\right)(\text { range })\end{array}$ & $1.1 \pm 1.6(0-6)$ & $6.8 \pm 8.0(0-27)$ & $5.5 \pm 9.9(0-30)$ \\
\hline $\begin{array}{l}\text { surgery for insulinoma }{ }^{\mathrm{b}} \\
\text { total/partial/enucleation/unknown }\end{array}$ & $1 / 7 / 13 / 4$ & $0 / 11 / 2 / 4$ & $1 / 7 / 4 / 2$ \\
\hline $\begin{array}{l}\text { recurrence of insulinoma } \\
\text { Yes/No }(\%)\end{array}$ & $4 / 19(17 \%)$ & $1 / 17(6 \%)$ & $0 / 13(0 \%)$ \\
\hline $\begin{array}{l}\text { PHPT } \\
\text { Yes/No (\%) } \\
\text { age at diagnosis }\left(\mathrm{yr}^{\mathrm{a}}\right) \text { (range) }\end{array}$ & $\begin{aligned} & 23 / 0(100 \%) \\
& 28.9 \pm 11.8(11-54)\end{aligned}$ & $\begin{array}{c}17 / 1(100 \%) \\
40.5 \pm 9.9(24-62)\end{array}$ & $\begin{array}{c}12 / 1(92 \%) \\
57.2 \pm 4.7(50-62)\end{array}$ \\
\hline $\begin{array}{l}\text { pituitary tumor } \\
\text { Yes/No }(\%) \\
\text { age at diagnosis }\left(\mathrm{yr}^{\mathrm{a}}\right) \text { (range) }\end{array}$ & $\begin{array}{c}8 / 15(35 \%) \\
24.8 \pm 7.5(11-35)\end{array}$ & $\begin{array}{c}12 / 6(67 \%) \\
41.7 \pm 11.1(27-62)\end{array}$ & $\begin{array}{c}5 / 8(38 \%) \\
53.0 \pm 16.1(25-64)\end{array}$ \\
\hline $\begin{array}{l}\text { MEN1 mutation } \\
\text { Yes/No /Not done }\end{array}$ & $18 / 1 / 4$ & $10 / 1 / 7$ & $8 / 1 / 4$ \\
\hline
\end{tabular}

Data do not include patients whose age at diagnosis is not known.

a, values are mean age $\pm \mathrm{SD}$. ${ }^{\mathrm{b}}$, When patients underwent partial pancreatectomy and enucleation of the tumor simultaneously, both procedures were counted independently. 
often occurs before adolescence $[1,9,17,18]$. In the MEN Consortium database, $13 \%$ of probands and $7 \%$ of affected family members had symptoms related to hypoglycemia before the diagnosis of MEN1.

Insulinoma was detected at a variety of ages before 70 years old and there was no apparent peak age of diagnosis (Fig. 1). It is particularly notable that a significant proportion of patients was diagnosed before age $20 \mathrm{yrs}$, which is in clear contrast to gastrinoma and nonfunctioning GEPNET; which were rarely if ever diagnosed before age $20 \mathrm{yrs}$. Interestingly, when the timing of appearance of hypoglycemia or suspected symptoms was closely investigated, many patients who were diagnosed with insulinoma during middle-age (30 - 49 years) had manifested hypoglycemic symptoms much earlier (Fig. 2), suggesting earlier development of insulinoma. It is rather surprising that $7 / 18$ patients diagnosed between age of 30 to 49 had either a hypoglycemic episode or had clinical histories symptomatic of hypoglycemia before age 30 yrs. The reason for this delay of diagnosis is not the subject of the present study, but it is possible that nonspecific symptoms and/or a relatively indolent clinical course may have delayed the point at which those patients visited hospital. Social factors such as work or family affairs may also have detracted from their willingness to visit hospital. The disproportionate female predominance among patients in the middleaged group may reflect such social factors (Table 3). This issue should be further clarified and may provide a clue to earlier diagnosis of insulinoma. Moreover, symptoms caused by hypoglycemia may have been misdiagnosed as other disorders, such as psycho-neurological diseases [19-21].

In contrast to the other age groups, patients whose insulinoma was detected after age 50 had distinct clinical features. These patients were predominantly probands, and insulinoma was simultaneously diagnosed with PHPT. 5/13 patients (38\%) had not experienced hypoglycemic symptoms before diagnosis. The exact age of onset of insulinoma in these aged patients is unknown, but it is reasonable to assume that their insulinomas had developed earlier in their life but were asymptomatic for a long period. Indeed, small- and clinically silent insulinomas are often not diagnosed until incidentally found at autopsy [22].

An interesting question is whether insulinoma develops earlier than other GEPNETs in MEN1 or is simply diagnosed earlier than other tumors because the clinical symptoms of insulinoma tend to appear earlier. Diagnosis of insulinoma may be relatively straightforward once hypoglycemia with elevated level of plasma insulin is confirmed. However, because of the nonspecific nature of hypoglycemic symptom such as fatigue, confusion, weakness or behavioral change, the duration of the symptomatic period before diagnosis can be lengthy [23]. In patients with nonfunctioning tumors, age at diagnosis among probands showed a peak during the 40 s, while those tumors were frequently found at a younger age in family members (Fig. 1C), suggesting that a long period had elapsed before the nonfunctioning tumors in probands were identified. In contrast, the age at diagnosis of gastrinomas in family members was unexpectedly older than that of the probands (Table 2). This may be attributable to the fact that gastrinoma in MEN1 is usually diagnosed by clinical symptoms and/or elevated plasma levels of gastrin, and not by imaging studies [11].

Recently, Ito et al. reported results of a nationwide epidemiological surveillance of GEPNETs in Japanese [14]. They estimated the total number of patients treated for pancreas NETs in the year 2005 was 2,845 $(95 \%$ CI $2,455-3,507) .10 \%$ of patients with pancreas NET and $14 \%$ of patients with insulinoma had MEN1, a proportion higher than other studies which reported the proportion of MEN1 among patients with insulinoma as $4-8 \%$ [24-26]; this may be due in part to a relatively high prevalence of insulinoma in Japanese patients with MEN1 [10]. The MEN Consortium database confirmed 314 patients with GEPNETs, most of whom are currently alive and under follow-up. It is likely that many patients with MEN1 with GEPNETs have been registered on both GEPNET surveillance and the MEN1 database.

According to Ito et al., only $1 \%$ of patients with GEPNETs were diagnosed before age of 20 years [14]. Although they did not show age-related prevalence of each functioning tumor, our present results suggest a high probability of the presence of MEN1 in patients with insulinoma diagnosed at young age, especially before 20 years old. Clinical guidelines for MEN1 released in 2001 recommended MENI genetic analysis for all patients with gastrinoma, based on the fact that $25 \%$ of gastrinoma patients have MEN1 [3]. We propose that MEN1 gene analysis should be offered to patients who have developed insulinoma before age of 20 years, even if they have no other MEN1related diseases or family history of MEN1. Indeed, since most subjects with MEN1 mutation do not man- 
ifest hyperparathyroidism or pituitary tumors before the age of 20 years, biochemical- and imaging studies for the purpose of surveillance of MEN1 will be of limited clinical utility. Among 13 patients who developed insulinoma before age of 20 years, only 4 patients manifested other MEN1-related diseases before the age of 20 years.

In conclusion, we analyzed the clinical features of insulinoma in patients with MEN1. While insulinoma occurs in a wide range of age groups, development of the tumor in younger patients was characteristic. Insulinoma before age of 20 years may be a strong indication of presence of MEN1, and detailed surveillance of MEN1 is warranted in these cases. Clinicians should also be aware that insulinoma can often be missed in middle-aged patients.

\section{Disclosure of Interest}

All authors have nothing to disclose.

\section{Funding}

This study was supported by a Grant from the Ministry of Health, Welfare and Labor, Government of Japan. [H22-Nanchi-Ippan-105] (to A. Sakurai).

\section{Acknowledgments}

We acknowledge the coauthors: Takuyuki Katabami (St. Marianna University), Miyuki Katai (Tokyo Women's Medical University), Takehito Igarashi (Nippon Medical School), Tsuguo Iwatani (Toranomon Hospital), Akihiro Miya (Kuma Hospital), and Ai Sato (Shinshu University). The authors are grateful to all physicians and surgeons who contributed to the construction of MEN1 database of Japanese patients by registering their patients. We also thank Dr. Tetsuhide Ito, Department of Medicine and Bioregulatory Sciences, Graduate School of Medical Sciences, Kyushu University, for valuable suggestions.

\section{References}

1. Marx S, Spiegel AM, Skarulis MC, Doppman JL, Collins FS, et al. (1998) Multiple endocrine neoplasia type 1: clinical and genetic topics. Ann Intern Med 129:484-494.

2. Piecha G, Chudek J, Wiecek A (2008) Multiple Endocrine Neoplasia type 1. Eur J Intern Med 19:99103.

3. Brandi ML, Gagel RF, Angeli A, Bilezikian JP, BeckPeccoz P, et al. (2001) Guidelines for diagnosis and therapy of MEN type 1 and type 2. J Clin Endocrinol Metab 86:5658-5671.

4. Lemos MC, Thakker RV (2008) Multiple endocrine neoplasia type 1 (MEN1): analysis of 1336 mutations reported in the first decade following identification of the gene. Hum Mutat 29:22-32.

5. Agarwal SK, Lee Burns A, Sukhodolets KE, Kennedy PA, Obungu VH, et al. (2004) Molecular pathology of the MEN1 gene. Ann N Y Acad Sci 1014:189-198.

6. Marx SJ 2001 Multiple endocrine neoplasia type 1. In: Scriver CR, Beaudet AL, Sly WS, Valle D eds. The Metabolic and Molecular Bases of Inherited Disease, 8th ed. McGraw-Hill.New York; 943-966.

7. Burgess JR, David R, Greenaway TM, Parameswaran V, Shepherd JJ (1999) Osteoporosis in multiple endocrine neoplasia type 1: severity, clinical significance, relationship to primary hyperparathyroidism, and response to parathyroidectomy. Arch Surg 134:1119-1123.

8. Wermers RA, Khosla S, Atkinson EJ, Achenbach SJ,
Oberg AL, et al. (2006) Incidence of primary hyperparathyroidism in Rochester, Minnesota, 1993-2001: an update on the changing epidemiology of the disease. $J$ Bone Miner Res 21:171-177.

9. Trump D, Farren B, Wooding C, Pang JT, Besser GM, et al. (1996) Clinical studies of multiple endocrine neoplasia type 1 (MEN1). QJM 89:653-669.

10. Sakurai A, Suzuki S, Kosugi S, Okamoto T, Uchino S, et al. (2012) Multiple endocrine neoplasia type 1 in Japan: establishment and analysis of a multicentre database. Clin Endocrinol (Oxf) 76:533-539.

11. Gibril F, Schumann M, Pace A, Jensen RT (2004) Multiple endocrine neoplasia type 1 and ZollingerEllison syndrome: a prospective study of 107 cases and comparison with 1009 cases from the literature. Medicine (Baltimore) 83:43-83.

12. Davì MV, Boninsegna L, Dalle Carbonare L, Toaiari M, Capelli P, et al. (2011) Presentation and outcome of pancreaticoduodenal endocrine tumors in multiple endocrine neoplasia type 1 syndrome. Neuroendocrinology 94:58-65.

13. Yao JC, Eisner MP, Leary C, Dagohoy C, Phan A, et al. (2007) Population-based study of islet cell carcinoma. Ann Surg Oncol 14:3492-3500.

14. Ito T, Sasano H, Tanaka M, Osamura RY, Sasaki I, et al. (2010) Epidemiological study of gastroenteropancreatic neuroendocrine tumors in Japan. J Gastroenterol 45:234-243. 
15. Oberg K (2010) Pancreatic endocrine tumors. Semin Oncol 37:594-618.

16. Jensen RT, Cadiot G, Brandi ML, de Herder WW, Kaltsas G, et al. (2012) ENETS Consensus Guidelines for the Management of Patients with Digestive Neuroendocrine Neoplasms: Functional Pancreatic Endocrine Tumor Syndromes. Neuroendocrinology 95:98-119.

17. de Vogelaere K, De Schepper J, Vanhoeij M, De Mey J, Goossens A, et al. (2006) Laparoscopic management of insulinoma in a child with multiple endocrine neoplasia type 1. J Laparoendosc Adv Surg Tech A 16:335-338.

18. Fabbri HC, Mello MP, Soardi FC, Esquiaveto-Aun AM, Oliveira DM, et al. (2010) Long-term follow-up of an 8 -year-old boy with insulinoma as the first manifestation of a familial form of multiple endocrine neoplasia type 1. Arq Bras Endocrinol Metabol 54:754-760.

19. Graves TD, Gandhi S, Smith SJ, Sisodiya SM, Conway GS (2004) Misdiagnosis of seizures: insulinoma presenting as adult-onset seizure disorder. J Neurol Neurosurg Psychiatry 75:1091-1092.

20. Piccillo GA, Musco A, Manfrini S, Mondati E, Guastella $\mathrm{T}$ (2005) Two clinical cases of insulinoma misdiagnosed as psychiatric conditions. Acta Biomed 76:118-122.
21. de Paiva AR, Castro LH, Rodrigues W Jr, Passarelli V, Jorge CL, et al. (2012) Multiple endocrine neoplasia type 1 presenting as refractory epilepsy and polyneuropathy - A case report. J Neurol Sci 315:172-175.

22. Service FJ, McMahon MM, O'Brien PC, Ballard DJ (1991) Functioning insulinoma--incidence, recurrence, and long-term survival of patients: a 60-year study. Mayo Clin Proc 66:711-719.

23. Boukhman MP, Karam JH, Shaver J, Siperstein AE, Duh QY, et al. (1998) Insulinoma--experience from 1950 to 1995 . West J Med 169:98-104.

24. Grant CS (2005) Insulinoma. Best Pract Res Clin Gastroenterol 19:783-798.

25. Nikfarjam M, Warshaw AL, Axelrod L, Deshpande V, Thayer SP, et al. (2008) Improved contemporary surgical management of insulinomas: a 25-year experience at the Massachusetts General Hospital. Ann Surg 247:165172.

26. Zhao YP, Zhan HX, Zhang TP, Cong L, Dai MH, et al. (2011) Surgical management of patients with insulinomas: Result of 292 cases in a single institution. J Surg Oncol 103:169-174. 